to course objectives and administered during the pilot. Competency on the post-test was set at $\geq 70 \%$. Tests and evaluations were analysed to guide curriculum improvements.

Results Ten participants took the pre-post test; mean scores were $60.3 \%(46 \%-81 \%)$ and $76.7 \%(70 \%-83 \%)$ respectively, with a mean increase of $16.4 \%(1 \%-37.5 \%)$. On course evaluations, all participants indicated that training content was relevant to their work. Areas of improvement included the need for better guidance on improving data quality and interpreting statistical test results.

Conclusion All participants demonstrated overall competency on knowledge and skills covered in training. Training will be revised and implemented among public health field workers throughout the country. We will continue to actively involve government and local partners to improve potential for sustainability.

\section{P2-377 A RURAL-URBAN COMPARISON OF THE PREVALENCE AND PATTERNS OF ELDER ABUSE IN OYO STATE, SOUTH WESTERN NIGERIA}

doi:10.1136/jech.2011.142976l.8

E Cadmus, ${ }^{*}$ E Owoaje, 0 Akinyemi, C Nwachukwu. University College Hospital, Ibadan, Oyo State, Nigeria

Introduction Globally, it has been documented that the population is ageing at an unprecedented rate. The issue of elder abuse has not been adequately addressed, especially in Nigeria because it has not yet been recognised as a serious matter. This study compares prevalence, patterns and factors associated with elder abuse among the elderly in a rural and an urban community in Oyo State, Nigeria.

Methods A comparative cross sectional survey was conducted among the elderly in selected rural and urban Local Government Areas in Oyo state, Nigeria, using interviewer administered questionnaires. Data obtained was analysed using SPSS version 16.

Results A total of 722 respondents were interviewed, $358(49.6 \%)$ in the urban location and $364(50.4 \%)$ in the rural area. The mean age of respondents was $70.92 \pm 9.21$ years (urban $70.22 \pm 8.91$ years: rural $71.62 \pm 9.47$ years $p<0.05$ ). Over half of the respondents were female $(56.0 \%)$ and married (58.2\%). The urban and rural prevalence of abuse are: physical abuse $21.8 \%$ vs $6.3 \%$; emotional abuse $16.8 \%$ vs $4.1 \%$; social abuse $27.4 \%$ vs $10.2 \%$ and financial abuse $20.9 \%$ vs $7.7 \%$ respectively. Sexual abuse $(0.6 \%)$ was reported only in the urban area. The positive predictors of elder abuse were locality, living arrangements and functional impairment.

Conclusion This study reveals that there is a high prevalence of all forms of elder abuse especially in the urban areas. There is a need to create awareness of the problem of elder abuse and formulate social security policies to protect the elderly.

\section{P2-378 WITHDRAWN}

\section{P2-379 EFFECTIVENESS OF A LOW-IMPACT EXERCISE PROGRAM IN LEBANESE MARGINALISED POSTMENOPAUSAL WOMEN WITH PSYCHOLOGICAL DISTRESS: A RANDOMISED CONTROLLED TRIAL}

doi:10.1136/jech.2011.142976l.9

${ }^{1} \mathrm{~B}$ R Saab, ${ }^{2} \mathrm{M}$ Chaaya, ${ }^{*}{ }^{2} \mathrm{~N}$ AlAyoubi, ${ }^{1} \mathrm{~T}$ Itani. ${ }^{1}$ American University of Beirut, Department of Family Medicine, Beirut, Lebanon; ${ }^{2}$ American University of Beirut, Epidemiology and population Health, Beirut, Lebanon

Background Psychological distress (PD) is common worldwide. Physical exercise is usually recommended by physicians to relieve PD among older adults. However, there is not yet strong enough evidence to support this recommendation.

Aim This study examined the effect of a low impact exercise program on marginalised Lebanese women with psychological distress.
Methods Community-dwelling women with a mean age of 56 years were randomised to either a low impact exercise program of three times a week for 6 weeks or a control group that received daily calcium tablets. The 12-item General Health Questionnaire (GHO12) was used to assess $\mathrm{PD}$, the main outcome measure, and intention-to-treat analysis was performed. A focus group discussion was then conducted with a group of women who completed the exercise program.

Results Sixty nine women were enrolled. Psychological distress was significantly lower at the completion of the study when compared to baseline levels in both intervention and calcium groups, whereby a drop in the GHO-12 was noted in all 69 women, but this drop did not differ significantly between the two groups.

Conclusion This study showed that light impact exercise did not result in significant improvement of PD though the women who participated in the exercise program reported improvement and asked to sustain this activity.

\section{P2-380 NEONATAL MORTALITY RISK FACTORS IN A RURAL PART OF IRAN: A NESTED CASE-CONTROL STUDY}

doi:10.1136/jech.2011.142976l.10

${ }^{1} \mathrm{R}$ Chaman, ${ }^{*} \mathrm{~K}$ H Naieni, ${ }^{2} \mathrm{M}$ Yunesian, ${ }^{1} \mathrm{M} \mathrm{G}$ Taramsari. ${ }^{1}$ Shahroud University of Medical Sciences, Shahroud, Iran; ${ }^{2}$ Tehran University of Medical Sciences, Tehran, Iran

Introduction Neonatal death has a complex causal framework and improvement of this health indicator is quite gradual. The aim of present study was evaluation of neonatal death risk factors in a substantial sample of Iranian neonates in a part of rural areas by using a relatively new design and modern analytic technique.

Methods and Materials This study was conducted as a nested casecontrol study and the study cohort was all of the neonates who were born in rural area of Kohgiluyeh and Boyerahmad province (South of Iran) during one calendar year (from March 2006 to March 2007). Due to occurrence of 97 cases of neonatal death in the studied cohort (6900 newborn), 97 controls were selected, resulting in a total sample size of 194.

Results Univariate conditional logistic regression for each variable was performed and any risk factors that showed marked association ( $p$ value $<0.2$ ) was selected for the next step analysis. In the final model (conditional logistic regression) LBW $(A O R=8.92)$, C-section $(\mathrm{AOR}=9.17)$, birth rank more than $3(\mathrm{AOR}=6.12)$, mother illiteracy $(A O R=3.96)$ and birth spacing $<24$ months $(A O R=5.45)$ showed significant statistical association ( $p$ value $<0.05$ ) with neonatal mortality.

Conclusion This study has identified; LBW, C-section, birth spacing $<24$ months, mother illiteracy and birth rank more than 3 as potential risk factors for neonatal mortality.

\section{P2-381 CHILDHOOD MORTALITY RISK FACTORS IN RURAL AREAS OF SHAHROUD, IRAN: A COMMUNITY BASED NESTED CASE-CONTROL STUDY}

doi:10.1136/jech.2011.142976l.11

${ }^{1} \mathrm{R}$ Chaman, ${ }^{*} \mathrm{M}$ H Emamian, ${ }^{2} \mathrm{~A}$ Alemi, ${ }^{2} \mathrm{~K}$ H Naieni, ${ }^{2} \mathrm{M}$ Shariati, ${ }^{1} \mathrm{M} \mathrm{G}$ Taramsari, ${ }^{1}$ E Ahmadnejhad. ${ }^{1}$ Shahroud University of Medical Sciences, Shahroud, Iran; ${ }^{2} T e h r a n$ University of Medical Sciences, Tehran, Iran

Background There is a complex causal framework for one-month to five-year-old child mortality. Hence, the improvement of this health indicator would also be quite gradual. This study was carried out to evaluate potential risk factors for death among children aged 1-59 months. 
Method A nested case-control study was conducted in rural areas of Shahroud, in the central region of Iran. We selected 65 child deaths from the 2000-2008 birth cohort of 10912 living newborns. A risk set sampling method was used to select controls (Case-Control ratio 1:2) who matched the cases in terms of age. The data were analysed using univariate and multivariate conditional logistic regression methods.

Results Significant associations with mortality were seen for: breastfeeding (OR $0.86,95 \%$ CI 0.79 to $0.93, p<0.001$ ), number of child cares (OR 0.90, 95\% CI 0.83 to $0.98, \mathrm{p}=0.017$ ) and low birth weight (OR 7.38, 95\% CI 1.38 to 39.58, $\mathrm{p}=0.020$ ).

Conclusion Incomplete breast feeding duration, insufficient number of child cares and low birth weight are important risk factors for 1-59 month child mortality in Iran. It appears that complex and multiple factors are involved in mortality of under-5-year-old children, so combined efforts will need to be applied to improve child health.

\section{P2-382 ILLEGAL STAY AND PRENATAL CARE IN IMMIGRANT PREGNANT WOMEN LIVING IN PORTUGAL}

doi:10.1136/jech.2011.142976l.12

E Coutinho, C Pereira, ${ }^{*}$ A Silva, J Duarte, N Veiga, P Nelas, M Ferreira, C Chaves. Cl \& DETS, Health School - Polytechnic Institute of Viseu, Viseu, Portugal

Background Immigration from low income countries represents a recent and increasing reality in Portugal. The legalisation process is slow and the illegal stay may represent a barrier to healthcare access. The objective of this study was to relate the illegal stay condition with the mother's obstetric surveillance.

Participants and Methods The sample included 499 immigrants living in Portugal, consecutively selected during the year 2010 in 21 Portuguese maternity hospitals. Data were collected in a face-to-face interview on the second day after delivery and with the consultation of medical hospital records. We considered adequate obstetric surveillance (AOS) if the mother had six or more appointments during pregnancy and the first occurred during the first trimester.

Results In this sample, the proportion of illegal immigrants was $10.7 \%$. The prevalence of AOS was $73.5 \%$, significantly lower in mothers in illegal situation $(59.1 \%$ vs $77.9 \%, p<0.01)$. AOS was associated with maternal age ( $\leq 25$ years $=57.3 \%, \quad 26-30$ years $=78.9 \%,>30$ years $=79.9 \%, p<0.01)$, women's education $(<6$ years $=60.6 \%, \quad 7-12$ years $=65.3 \% \quad>12$ years $=90.9 \%, \quad p<0.01)$, marital status (single $/$ divorced $=62.0 \%$, married $=79.9 \%, p<0.01$ ), profession (white collar $=84.5 \%$, blue collar $=68.3 \% p<0.01$ ) wanted pregnancy (yes $=81.4 \%, \mathrm{no}=50.5 \%, \mathrm{p}<0.01$ ). After adjustment by non conditional logistic regression for mothers age, education and marital status, the illegal stay is associated with $\mathrm{AOS}(\mathrm{OR}=0.48$; 95\% CI 0.29 to 0.82 )

Conclusion Among immigrant pregnant women living in Portugal, the AOS is associated with illegal stay condition.

\section{P2-383 LIFETIME FOLLOW-UP OF MYCOBACTERIUM TUBERCULOSIS INFECTED INDIVIDUALS INCLUDING THOSE WITH SUBSEQUENT HIV INFECTION}

\section{doi:10.1136/jech.2011.142976l.13}

\begin{abstract}
${ }^{1,2} \mathrm{~A}$ Crampin, ${ }^{*}{ }^{1} \mathrm{H}$ Longwe, ${ }^{1} \mathrm{D}$ Mulawa, ${ }^{1} \mathrm{~L}$ Mwaungulu, ${ }^{2} \mathrm{~J}$ Glynn, ${ }^{2} \mathrm{H}$ Dockrell, ${ }^{2} \mathrm{~N}$ French, ${ }^{2} \mathrm{P}$ Fine. ${ }^{1}$ Karonga Prevention Study, Chilumba, Malawi; ${ }^{2}$ London School of Hygiene and Tropical Medicine, London, UK
\end{abstract}

Introduction The assumption that infection with $M$ tuberculosis is life-long in the absence of treatment underlies the "statistic" that one third of people worldwide are currently infected. Exploration of the validity of this statement and the contribution of this reservoir to later disease are critical, given the WHO target of elimination of TB by 2050. HIV-positive individuals are assumed to be at high risk of "remotely" acquired $M$ tuberculosis infection when their immunity declines. Understanding individuals who clear or control infection is key to identifying correlates of protection and requires a well defined long term epidemiological cohort.

Methods A cohort of 2000 individuals with strong evidence of $M$ tuberculosis infection (tuberculin skin test [TST] $>20 \mathrm{~mm}$ without active disease at baseline) in Malawi were followed up after 25 years. Outcomes (active TB, death, departure) were recorded. A sample of survivors were investigated for HIV status and CD4 count, TST and commercial interferon gamma release assay (T-Spot. TB). A sub-sample were re-tested immunologically after isoniazid treatment.

Results Life-time risk of active TB was approximately $8 \%$, with highest incidence in the first 2 years. We identified groups who appear to have resolved infection: HIV-positive immunocompromised survivors with no evidence of $\mathrm{TB}$, and HIV-negative individuals with complete absence of characteristic immunological responses. Some individuals showed exaggerated immune response indicating ongoing immune stimulation.

Conclusions Latent $M$ tuberculosis infection may resolve without treatment and natural, identifiable, "protected" phenotypes may exist. These findings have implications for both control of the reservoir of latent infection and the potential for evaluation of vaccines.

\section{P2-384 RISK OF PRETERM BIRTH: A CASE-CONTROL POPULATION-BASED}

doi:10.1136/jech.2011.142976l.14

${ }^{1} \mathrm{P} L$ de Assunção, ${ }^{*}{ }^{1} \mathrm{H}$ M D Novaes, ${ }^{1} \mathrm{G}$ P Alencar, ${ }^{2} \mathrm{~A} S$ de Oliveira Melo, ${ }^{1} \mathrm{M} F$ de Almeida. ${ }^{1}$ University of São Paulo, São Paulo, São Paulo, Brazil; ${ }^{2}$ Institute of Integral Medicine Prof. Fernando Figueira, Recife, Pernambuco, Brazil

The prevalence of preterm birth has increased in recent years and is a worldwide public health problem. To study the risk factors for preterm birth we examined hospital deliveries in residents in the city of Campina Grande/PB, Brazil. The case-control populationbased study was conducted from June 2008 to May 2009. The medical data and interviews of mothers of 341 preterm births (cases) and 424 controls were conducted. Logistic multiple regression model, based on a hierarchised conceptual modelling, approach was performed. The risk factors for preterm birth were: previous preterm birth ( $\mathrm{OR}=2.32 ; 95 \% \mathrm{CI} 1.25$ to 4.29$)$, inadequate prenatal care (category II - three or more negative prerequisites) $(\mathrm{OR}=2.15$; $95 \%$ CI 1.40 to 3.27$)$, inadequate maternal weight gain $(\mathrm{OR}=2.33$; $95 \%$ CI 1.45 to 3.75 ), physical damage to the mother during pregnancy $(O R=2.10 ; 95 \%$ CI 1.22 to 3.60$)$, hypertension pressure $(\mathrm{OR}=17.08 ; 95 \%$ CI 3.67 to 79.43 ), hospitalisation during pregnancy $(\mathrm{OR}=5.64 ; 95 \% \mathrm{CI} 3.47$ to 9.15$)$, amniotic fluid volume changes $(\mathrm{OR}=2.28 ; 95 \% \mathrm{CI} 1.32$ to 3.95$)$, vaginal bleeding $(\mathrm{OR}=1.54 ; 95 \%$ CI 1.01 to 2.34$)$ and multiple gestation $(\mathrm{OR}=22.65$; $95 \%$ CI 6.22 to 82.46). The per capita income less than the minimum wage was a protective factor $(\mathrm{OR}=0.63$; $95 \%$ CI 0.39 to 0.99). The risk factors were similar to those observed in other national and international studies, except for the result of varying socioeconomic level. The high prevalence of poverty and low educational level, higher than in studies in the South in both outcomes, may have contributed to this result. Further studies are needed on the complexity of causal chains in preterm delivery in different contexts and differentiation by subtypes (spontaneous and indicated pre-term births). 